\title{
Research on the Internationalization of Printing Engineering Education Facing the Belt and Road Yong-gang YANG ${ }^{1}$, Qiao-zhuo $\mathrm{GAO}^{2, \star}$ and $\mathrm{Ke} \mathrm{YANG}^{1}$ \\ ${ }^{1}$ Beijing Institute of Graphic Communication, Beijing, China \\ ${ }^{2}$ The Emerald City Branch of Beijing Primary School, Beijing, China \\ ${ }^{*}$ Corresponding author
}

\begin{abstract}
Keywords: The Belt and Road; Printing Engineering Education; Internationalization; Excellent Engineer Training Program.
\end{abstract}

\begin{abstract}
Insisting on the new mode of internationalized talents training with "bringing in and going out" is the only way to carry out the internationalization of printing engineering education. Taking Beijing Institute of Graphic Communication as an example, this paper introduces the current status and work basis of the internationalization of the school printing engineering education from five aspects. At the same time, the international environment, technical level and regional differences in international work are also given. Finally, it expounds the implementation path of the internationalization of the printing engineering education oriented to the "the Belt and Road", which has certain reference for the local colleges to promote the internationalization of higher education.
\end{abstract}

\section{Introduction}

At present, the tide of globalization is unstoppable. "the Belt and Road" initiative has advanced in depth and achieved remarkable results, reflecting the new trends in global development that are discussed, built, and shared together. In the process of globalization, education plays a fundamental and leading role. The development of Chinese universities should not only take root in China, but also look to the world and promote the internationalization of higher education. This is the only way to build a first-rate university and a strong education nation.

Printing is one of the "four great inventions" in ancient China, and the printing civilization has long been renewed. In the education positioning of the Beijing Institute of Graphic Communication, it is a constant theme and historical mission to inherit the time-honored printing civilization of China and to innovate media science and technology and culture [1]. The school's printing engineering major is the longest running and most profound undergraduate major, and it opened the precedent of China's printing higher education. At present, our school's printing engineering major is a state-level specialty, the Ministry of Education's "excellent engineer training program" pilot professional and Beijing's first batch of "first-class professional." In the new era, to achieve the connotative development and characteristic development of printing engineering higher education, and to take the road of sustainable development, we must strengthen the pace of internationalization of printing engineering education, and insist on the new mode of internationalized talents training with "bringing in and going out".

\section{Current Status and Foundation of the Internationalization of Printing Engineering Education in Our School}

In order to serve the national "the Belt and Road" development strategy, according to the Ministry of Education's "Education to Promote the Construction of 'the Belt and Road' Education Initiative" and the "Several Opinions on the Education Opening-up Work in the New Era", the cooperation focus of "the Belt and Road" education initiative has been truly implemented to prompt the education mission. According to this, leaders of the Beijing Institute of Graphic Communication led the delegation to Pakistan, Russia, India, Mongolia and Nepal, laid a solid foundation in promoting "the Belt and Road" countries and regions cooperation in the printing industry, printing 
and packaging equipment, printing higher education and other aspects.

\subsection{Constructing an international education institution and team with a global perspective and strong engineering practice and high business level}

Since the "Twelfth Five-Year Plan" period, the school has attached great importance to the strategy of "Going Out" and "Bringing In" for print talents and has taken active actions. At the end of 2012, the School of International Education was established for carrying out "the Belt and Road" countries in technology, materials, equipment and education cooperation in printing and packaging, publishing and communication, design and art, and new media and other fields. In particular, in the field of printing engineering education, the school established the "Teaching Professional Internationalization Course Teaching Team" in 2015 (school-level excellent teaching team in 2016), and successfully applied for a School-level key teaching reform projects, "international cooperation model for educational research", in 2016. Up to now, our university has enrolled more than 300 international students from 15 countries including India, Pakistan, Mongolia, and Nepal. We have implemented the strategy of "inviting in" for the printing talents.

\subsection{Establishing Bisheng Excellence Class and Implementing a Talent Training Program for Outstanding Engineers}

The printing engineering major of our school is the second batch of the pilot program of the "Excellent Engineer Education Training Program" of the Ministry of Education. In December 2012, the school selected 35 people from the three undergraduate majors of the printing and packaging engineering of level 2011 and set up the first session Bisheng Excellence Class. The Class of Excellence has adopted a brand-new training program to carry out innovative engineering education based on cooperation between schools and enterprises. Up to now, there have been six classes that have been completed. Classes of 2011, 2012 and 2013 students have successfully graduated, with a graduation rate of $100 \%$. After systematic practice education and training, students have noticeably improved their awareness of innovation and entrepreneurship and their engineering practice capabilities have rapidly increased which makes them be very popular in the job market.

\subsection{Opening a new printing technology training class to train international printing and packaging talents for the "The Belt and Road" countries}

India's "3D Printing and Printing Electronics" training program for young technicians was hold in schools from May to August 2017. The first group including 7 members was selected by the All India Printing Alliance (AIFMP), all from India's printing business family and printing professional teachers in Indian College. We have conducted systematic and all-round training in related theories, research innovations, corporate internship practices and other aspects of 3D printing and printed electronics. Our instructors taught in English in all aspects, combined with practical exercises and trainings, and achieved good training results. During the training process, the trainees also took an internship in printing company in Tangshan, Hebei, to understand, visit, inspect, and investigate the many key products of Yutian Printing Machinery and other variable companies. By these, actions played an important role in promoting the national "The Belt and Road" strategy.

\subsection{Organizing a Printing Confucius Institute to set an example for cooperation in printing higher education, and achieving the sharing of the printing and packaging industry}

The school proposes to use the "The Belt and Road" approach, through school-enterprise cooperation, and to take advantage of the unique characteristics of the industry to build the first Confucius Institute in China's printing industry, implement the "going out" principle of printing education, and train international printing professionals to achieve Printing and packaging industry sharing. The Confucius Institute for Printing is planned to establish in Gwadar, Pakistan, to implement the "production line + person" talent training plan [2]. It can organically integrate industrial cooperation with education and training, build a communication and cooperation platform for Chinese printing and packaging companies, and improve the international influence of printing and packaging education and industry of China in "The Belt and Road". 


\section{Current Problems in the Internationalization of Printing Engineering Education}

Facing to the countries and districts alongside "the The Belt and Road" cooperate deeply in printing engineering technology, equipment, and education and promote the progress of printing engineering education internationalization.

\subsection{Global politic environment and domestic situation still exert a negative impact on 'the belt and the road' strategy}

"The The Belt and Road" refers to the Silk Road Economic Belt and the $21^{\text {st }}$ century Maritime Silk Road. As a strategy initiated by China and promoted by high level, 'the belt and the road' has far-reaching strategic significance for China's modernization and standing in the leader position of the world. Nowadays many countries and districts alongside 'the belt and the road' are still haunted deeply by wars, poverty and hungry. Social instability, deep socioeconomic divisions, and religious conflicts have brought uncertainty and negative impact on project implement and printing engineering education internationalization. At the same time, with the high pressure of labor market, supporting policies for innovation and entrepreneurship need to be improved, and overseas students' entrepreneurship and employment preferences need further improvement. Therefore, the process should run orderly, steady, and safely with the creative working thoughts under the guidance of domestic strategy and the support of relevant apartments.

3.2 Horizontal distance between project resources and team Full and all-round development of the "The Belt and Road" strategic cooperation is still insufficient

China is one of the four ancient civilizations, and also the largest and fastest development of emerging economies in the world. China connected other national and regional civilization together through the "The Belt and Road". Carrying out a full range of printing engineering international cooperation, we still need to have absolute advantages in talents, technology, material and equipment to hold the initiative. After nearly forty years of reform and opening up, China has grown into the world's largest printing and packaging market, but the level of printing and packaging equipment still has long way to go. The quality and processing precision of some materials still have a gap compared with the high precision abroad, and the number of "excellent engineers" kind of compound applied talents is still unable to meet market demand.

\section{The Implementation of "the Belt and Road" for the Internationalization of Printing Engineering Education}

4.1 Take the "double-class" construction as the guide, carry out the construction of the first-class professional connotation, and improve the professional strength of printing engineering

At present, China's "double first-class" construction is beginning to open its curtains. For colleges and universities with distinctive characteristics like ours, we will focus on cultivating composite application talents for the industry. The project should be led by the construction of "first-rate profession", and be based on "the integration of ideological and political education and professional comprehensive education, the integration of cultural theory education with innovation and entrepreneurship education, the integration of internal basic education of disciplines with the practice of off-campus engineering," and "closeness to the industry." "Three-convergence and three-closeness" talent cultivation concept with special needs, close to Beijing-Tianjin-Hebei coordinated development strategy and students' growth goals. Guided by the new concept of professional orientation, updating the ideas of professional education, and focusing on professional planning, personnel training programs, We will make great efforts in practical teaching resources, the construction of curriculum and characteristic textbooks, and the construction of teaching staff. We will increase investment, improve the ability and level of professionalism in printing engineering, and realize the transition from traditional engineering to new engineering. 
4.2 Taking the pilot of the "Excellent Engineer Education and Training Program" of the Ministry of Education as an opportunity to strengthen school-enterprise cooperation and implement joint construction to cultivate practical and innovative talents

In 2012, the printing engineering major of our school became the second batch of pilot programs of the "Excellent Engineer Education and Training Program" of the Ministry of Education and established the "Bisheng Excellence Class". The project should rely on the city-level practical teaching platform and the municipal scientific research and innovation platform to create a "four-in-one" engineering practice teaching system that is "skills training-corporate internship-scientific research-practical innovation" to strengthen schools and enterprises. The cooperation between universities and research institutes explores "taking a joint discipline competition as a starting point and focusing on improving students' innovative thinking; taking joint research projects as a starting point, and making efforts to improve students' scientific literacy; using joint graduation design as a starting point and focusing on "Three Unions, Three Improvements" in Practice to Improve Students' Comprehensive Ability: Practice and Innovation. The project team should also actively organize, contract or organize students to participate in the industry's top professional skills competitions or domestic and foreign academic competitions and innovation and entrepreneurship activities, pay attention to guiding students with special skills to participate in professional skills assessment, emphasizing cross-study and research, engineering and learning, through competitions and training, In the activities to exercise students' sense of innovation, enhance students' ability of engineering innovation. At the same time, relying on Beijing University's three major programs including "Wai Pei", "Double Penetration" and "Practical Training", we have expanded external resources, enriched practical teaching methods, and greatly improved the quality of personnel training and internationalization.

4.3 Taking the International Education Institute and the Confucius Institute of Printing in our school as the school-running institution, relying on the resources of the project team to carry out academic education and training classes to effectively serve the "the Belt and Road" strategy

In September of 2107, the School of International Education of our university enrolled more than 300 international students from countries along the "the Belt and Road" such as India, Pakistan, Mongolia and Nepal to carry out printing and packaging, publishing and communication, design and art, and new media. Discipline education and short-term training courses. The printing industry is an industry that has gained growth by upgrading the advanced nature of equipment and improving the quality of printed matter in a short period of time. In the service process for overseas markets, China's printing industry must not only follow up the domestic talents, but also cultivate the local talents of the equipment export target countries, realize the output of the production line and the cultivation of talented people, and create a "production line plus person" training mode, localization of services. Therefore, I revised and actively planned the Confucius Institute for Printing, focusing on service to countries and regions such as South Asia, West Asia, and Central Asia along "the Belt and Road", and shared our long-standing printing culture, cutting-edge printing technology, and modern printing education to achieve a win-win situation [4]. The expansion of our university's influence in countries and regions along the "the Belt and Road" has made our school more confident in building distinctive and high-quality publishing media universities.

4.4 Taking the "The Belt and Road" national talent cultivation base project as the lead, comprehensively promote the internationalization education of printing projects, and continue to expand our school's distinctive professional advantages and international influence

In September 2017, our university was selected as one of the first batch of 30 bases in Beijing's "the Belt and Road" national talent cultivation base project. This is to deepen the educational exchange and pragmatism between our university and related institutions along the "the Belt and Road" countries and regions. Cooperation will increase the mutual understanding and awareness of 
both parties and accelerate the promotion of the internationalization of printing engineering education in our university. The printing engineering major of our school ranks among the top in the same or similar professional rankings of similar institutions in the country for five consecutive years. The upstream and downstream majors (such as publishing and communication, design art and new media) are also in the leading position in the same disciplines or professions in the country. It has effectively guaranteed the gathering of specialized resources for printing engineering and the creation of international brands. Serving the country's "the Belt and Road" strategy to ensure that the advantages and characteristics of the professional advance, will not only get the support of the whole school, will also be highly recognized by Beijing.

\section{References}

[1] Luo Xueke, Xie Dan. Thinking and exploration of the internationalization of Higher Education under the background of "the belt and road" [J], Beijing Education - Higher Education, 2017, (12): $14-17$.

[2] Dong Tao. A study on the countermeasures of the internationalization of higher education in China under the background of "the Belt and Road" [J], The Science Education Article Collects, 2017, (8): 120-121.

[3] Bailu. Approach to the strategy of "The Belt and Road" to guide the internationalization of Higher Education [J], New west, 2015, (23): 121,125.

[4] Lujie. Thinking and practice on the international talents training in colleges under the strategic background of "The Belt and Road" [J], Journal of Mudanjiang College of Education, 2018, (2): 31-33. 